\title{
Increased C-reactive protein is associated with the severity of thoracic radiotherapy- induced cardiomyopathy
}

\author{
Justin M. Canada ${ }^{1 *+} \mathbb{D}$, Georgia K. Thomas ${ }^{1 \dagger}$, Cory R. Trankle', Salvatore Carbone ${ }^{1,2}$, Hayley Billingsley ${ }^{1,2}$, \\ Benjamin W. Van Tassell ${ }^{1,3}$, Ronald K. Evans ${ }^{2}$, Ryan Garten ${ }^{2}$, Elisabeth Weiss ${ }^{4}$ and Antonio Abbate ${ }^{1,5}$
}

\begin{abstract}
Background: Irradiation of the heart during cancer radiotherapy is associated with a dose-dependent risk of heart failure. Animal studies have demonstrated that irradiation leads to an inflammatory response within the heart as well as a reduction in cardiac reserve. In the current study we aimed to evaluate whether inflammatory biomarkers correlated with changes in cardiac function and reserve after radiotherapy for breast or lung cancer.

Methods and results: We studied 25 subjects with a history of breast or lung cancer without a prior diagnosis of cardiovascular disease or heart failure, 1.8 years [0.4-3.6] post-radiotherapy involving at least 5 Gray (Gy) to at least $10 \%$ of the heart. High-sensitivity C-reactive protein (CRP) was abnormal ( $\geq 2 \mathrm{mg} / \mathrm{L})$ in 16 (64\%) subjects. Cardiac function and reserve was measured with Doppler echocardiography before and after exercise and defined as leftventricular ejection fraction (LVEF), early diastolic mitral annulus velocity (e'), and increase in LV outflow tract velocity time integral cardiac output (cardiac reserve) with exercise. Subjects with abnormal CRP had significantly lower LVEF (51 [44-59] \% vs 61 [52-64] \%, $P=0.039)$, lower e' $(7.4$ [6.6-7.9] cm/sec vs 9.9 [8.3-12.0] cm/sec, $P=0.010)$, and smaller cardiac reserve $(+1.5[1.2-1.7] \mathrm{L} / \mathrm{min}$ vs $+1.9[1.7-2.2] \mathrm{L} / \mathrm{min}, P=0.024)$.

Conclusion: Elevated systemic inflammation is associated with impaired left-ventricular systolic and diastolic function both at rest and during exercise in subjects who have received radiotherapy with significant incidental heart dose for the treatment of cancer.
\end{abstract}

Keywords: Radiotherapy, Cardiotoxicity, Inflammation

\section{Introduction}

Radiotherapy remains a cornerstone of treatment for many cancers. Lung, esophageal, breast, and proximal gastric cancers still receive incidental radiation to the heart as part of curative intent or palliative care [1-4]. Contemporary and more sophisticated administration of thoracic radiotherapy and systemic immunotherapy have been effective in reducing cancer-related mortality and limiting exposure to the heart. However, radiotherapy to the chest increases the risk for cancer-unrelated morbidity and mortality, especially cardiovascular mortality, in a dose-dependent manner [1,5-8]. Furthermore, recent

\footnotetext{
* Correspondence: Justin.M.Canada@vcuhealth.org

†ustin M. Canada and Georgia Thomas contributed equally to this work.

${ }^{1}$ VCU Pauley Heart Center, Virginia Commonwealth University, P.O. Box

980335, 1200 E. Broad Street, Richmond, Virginia 23298, USA

Full list of author information is available at the end of the article
}

studies have shown that major adverse cardiovascular events, like acute myocardial infarction and stroke, are likely occurring earlier post-treatment than previously thought [1,5]. In a well-characterized cohort of 945 women with breast cancer who had received a mean radiation dose to the heart of 2.5 Gray (Gy), Saiki et al. showed that 60 patients $(6 \%)$ developed new-onset heart failure (HF) $5.8 \pm 3.4$ years following radiotherapy [9]. When a nested case-control matched analysis was performed, the mean heart dose was higher in HF cases $(3.3 \pm 2.7 \mathrm{~Gy})$ than controls $(2.1 \pm 2.0 \mathrm{~Gy} ; P=0.004)$, and the odds ratio ( $95 \%$ confidence interval) for HF per logchange in mean cardiac radiation dose was 9.1 (3.424.4), thus highlighting that even relatively small doses of radiotherapy to the heart have the potential to cause HF [9]. Moreover, exercise intolerance, a surrogate of

(c) The Author(s). 2020 Open Access This article is distributed under the terms of the Creative Commons Attribution 4.0 International License (http://creativecommons.org/licenses/by/4.0/), which permits unrestricted use, distribution, and 
impaired cardiac reserve and a strong predictor of allcause and cancer-related mortality [10, 11], seems to appear early after radiotherapy and may contribute significantly to impairments in quality of life [12-15].

Commonly used tools to assess cardiac function (i.e., resting left-ventricular ejection fraction [LVEF] by echocardiography) are notoriously insensitive to minor injury, and therefore subtle changes can go unnoticed. Moreover, a large portion of patients presenting with new-onset heart failure are expected to have preserved LVEF [16]. In Saiki et al., $64 \%$ of patients with new-onset HF after radiotherapy had preserved LVEF [9]. Using cardiopulmonary exercise testing, we have recently described an early dosedependent inverse relationship between radiation dose to the heart and peak oxygen consumption in patients who had received radiotherapy to the chest driven primarily by impairments in cardiac diastolic reserve [13].

The mechanisms by which radiotherapy induces impaired cardiac reserve is complex. Preclinical studies have shown that there is an acute series of events following radiotherapy characterized by inflammation resulting in impaired contractile reserve, followed by cell death leading to a reparative fibrotic response in the pericardium, myocardium and valvular structures [17-20]. Activation of pro-inflammatory pathways likely play an important role in the early changes seen following radiotherapy. Animal models have demonstrated reversible systolic dysfunction and reduced LV contractility reserve following injections of interleukin (IL)- $1 \beta$, the prototypical pro-inflammatory cytokine, in otherwise healthy mice, whereas mice pretreated with anakinra, an IL-1 receptor antagonist, or an IL-1 $\boldsymbol{\beta}$ antibody, were spared from these detrimental effects [21]. Additionally, mice injected with plasma from patients with stable chronic systolic HF and elevated plasma levels of C-reactive protein (CRP) showed normal resting systolic function but significantly impaired contractile reserve [22]. In the current study we sought to determine whether CRP, a systemic inflammatory biomarker and surrogate for IL-1 activity, could identify patients with radiotherapyinduced impairment in cardiac function or reserve.

\section{Methods}

We conducted a single-center prospective study enrolling patients with a history of breast or lung cancer who had received thoracic radiotherapy with a resultant significant cardiac dose (at least 5 Gy to at least $10 \%$ of the heart) as part of intended curative treatment for malignancy. These subjects did not have a prior diagnosis of cardiovascular disease or heart failure. All patients were at least 18 years of age, had adequate acoustic windows for echocardiography, and had to be able to perform treadmill exercise testing with ventilatory gas-analysis. All patients underwent informed consent prior to enrollment. The study was approved by the Virginia Commonwealth University Institutional Review Board.

A blood sample was obtained to evaluate the biomarker high-sensitivity CRP (hsCRP). Elevated systemic inflammation was defined as an hsCRP $\geq 2.0 \mathrm{mg} / \mathrm{L}$ [23]. All patients underwent transthoracic Doppler echocardiography at rest and immediately post-exercise to evaluate cardiac systolic and diastolic function. Symptomlimited exercise was performed utilizing a conservative treadmill ramping protocol using percentage of agepredicted maximal heart rate (\%APMHR) to quantify subject effort. Tissue Doppler-derived early transmitral flow velocity (E), early diastolic mitral annular velocities $\left(e^{\prime}\right)$ averaged between the lateral and septal annulus - a measure of diastolic function - and the change in leftventricular outflow tract velocity time integral cardiac output $(\triangle$ LVOT VTI CO) with exercise - a measure of cardiac reserve - were obtained according to standard recommendations $[24,25]$. Since estimation of the cross-sectional area of the left-ventricular outflow tract represents a potential source of error, the velocity time integral alone was used as a surrogate for cardiac output measurement [26].

Table 1 Characteristics of the Cohort

\begin{tabular}{ll}
\hline Variables & Median [IQR] or N (\%) \\
\hline Age, years & $63[59-66]$ \\
Female, $\mathrm{n}(\%)$ & $15(60 \%)$ \\
Caucasian, $\mathrm{n}(\%)$ & $16(64 \%)$ \\
African-American, $\mathrm{n}(\%)$ & $9(36 \%)$ \\
Body mass index, kg/m² & $26.4[22.6-30.2]$ \\
Cancer Type & \\
$\quad$ Lung & $15(60 \%)$ \\
$\quad$ Breast & $10(40 \%)$ \\
Time since Cancer Diagnosis, years & $2.4[1.1-3.9]$ \\
Prior chemotherapy & $21(84 \%)$ \\
Time since completion of chemotherapy, years & $1.5[0.5-3.0]$ \\
Time since completion of Radiotherapy, years & $1.8[0.4-3.6]$ \\
Hormonal modulating therapy & $7(28 \%)$ \\
(Breast cancer only) & \\
MCRD, Gy & $5.4[3.7-14.7]$ \\
C-reactive protein, mg/L & $3.0[1.7-6.9]$ \\
\%APMHR & $93[78-102]$ \\
LVEF, \% & $52[47-61]$ \\
Doppler echo e' velocity (cm/sec) & $7.6[7.0-9.6]$ \\
Delta LVOT VTI CO (L/min) & $1.6[1.5-1.9]$ \\
\hline
\end{tabular}

Data are listed as $\mathrm{n}$ (\%) or median (interquartile range). Abbreviations: $\mathrm{kg} / \mathrm{m}^{2}$ Kilograms per meter squared, MCRD Mean cardiac radiation dose, Gy Gray units, $m g / L$ Milligrams per liter, \%APMHR Percentage of age-predicted maximal heart rate, $L V E F$ Left-ventricular ejection fraction, $e^{\prime}$ Doppler early diastolic mitral annular velocity, $\mathrm{cm} / \mathrm{sec}$ Centimeters per second, LVOT VTI CO Leftventricular outflow tract velocity time integral cardiac output with exercise, $L /$ min Liters per minute. 
Table 2 Distribution of comorbid conditions or statin use in those without and with elevated hsCRP

\begin{tabular}{|c|c|c|c|}
\hline Categorical Variables & $\begin{array}{l}\text { hsCRP }<2 \mathrm{mg} / \mathrm{L} \\
(n=9)\end{array}$ & $\begin{array}{l}\text { hsCRP } \geq 2 \mathrm{mg} / \mathrm{L} \\
(n=16)\end{array}$ & $P$-value \\
\hline History of chemotherapy & $7(78 \%)$ & $14(88 \%)$ & 0.602 \\
\hline Cancer type (Breast vs. Lung) & & & 1.000 \\
\hline Breast cancer & $4(44 \%)$ & $6(38 \%)$ & \\
\hline Lung cancer & $5(56 \%)$ & $10(63 \%)$ & \\
\hline History of anemia & $1(11 \%)$ & $4(25 \%)$ & 0.621 \\
\hline Obesity & $1(11 \%)$ & $6(38 \%)$ & 0.355 \\
\hline Hypertension & $4(44 \%)$ & $10(63 \%)$ & 0.434 \\
\hline Dyslipidemia & $5(56 \%)$ & $5(31 \%)$ & 0.397 \\
\hline Diabetes Mellitus & $1(11 \%)$ & $5(31 \%)$ & 0.364 \\
\hline Current Smoker & $2(22 \%)$ & $4(25 \%)$ & 1.000 \\
\hline Sedentary Lifestyle & $3(33 \%)$ & $8(50 \%)$ & 0.677 \\
\hline Statin Use & $3(33 \%)$ & $5(31 \%)$ & 1.000 \\
\hline Hormone therapy & $3(33 \%)$ & $4(25 \%)$ & 0.673 \\
\hline
\end{tabular}

Legend: Distribution of nominal variables expressed as Yes or No based on medical history and/or medication use. Proportion of those with the presence of categorical comorbid conditions, statin use, or hormone therapy use are reported as number (\%). Obesity defined as a body mass index $\geq 30 \mathrm{~kg}$ per meter squared

Data are reported as median and interquartile range [IQR] for potential deviation from a Gaussian distribution. Spearman correlation coefficients were estimated to assess correlations between CRP and cardiac function from echocardiography variables. A Mann-Whitney U test was performed to compare those with and without elevated systemic inflammation (hsCRP $\geq 2.0 \mathrm{mg} / \mathrm{L}$ versus $<2.0 \mathrm{mg}$ / L). Fisher's exact test was used to assess differences in the presence of categorical (Yes/ No) comorbid conditions based on medical history (prior chemotherapy, cancer type (breast vs. lung), anemia, obesity, hypertension, dyslipidemia, diabetes mellitus, current smoker, sedentary lifestyle) or agents that have a known modifyingassociation with CRP (i.e., statins, hormone therapy) between those with and without elevated hsCRP.

\section{Results}

Table 1 provides the demographic and clinical characteristics of the entire cohort.

Sixteen (64\%) subjects had elevated hsCRP $(\geq 2.0 \mathrm{mg} / \mathrm{L})$. The \%APMHR achieved during exercise testing was not different between those with and without elevated hsCRP
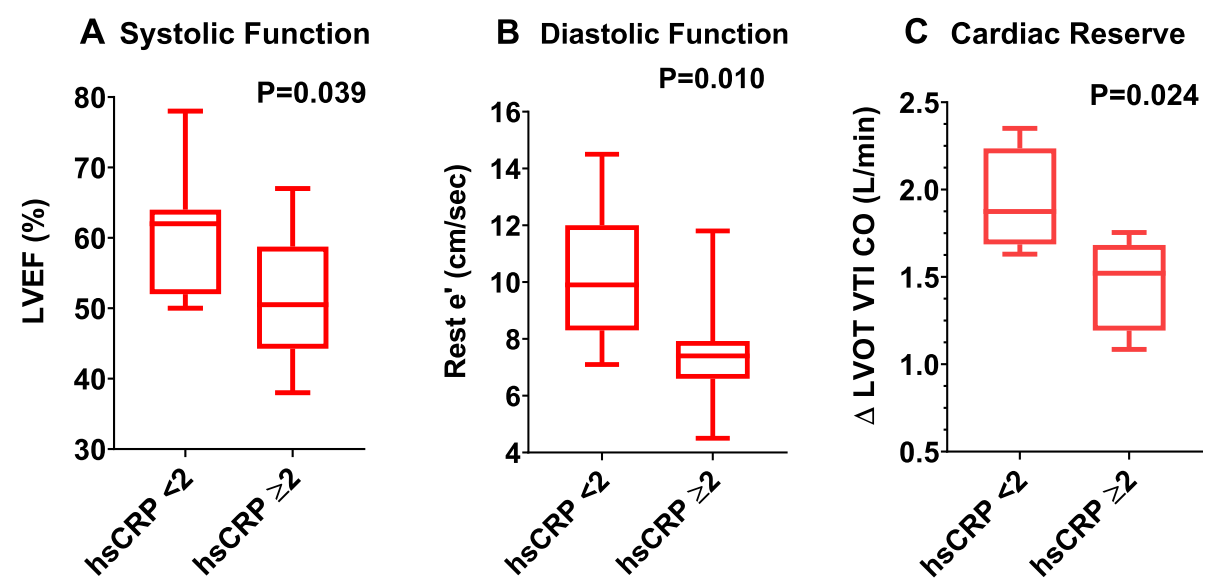

Fig. 1 Impaired cardiac function in patients with elevated C-reactive protein levels after radiotherapy therapy for cancer. Transthoracic Doppler echocardiography at rest and at immediately post-exercise was used to measured left ventricular ejection fraction (Panel a), mitral annulus early diastolic velocity for myocardial relaxation (Panel b), and the change in left-ventricular outflow tract velocity time integral cardiac output (Panel $\mathbf{c}$ ) with exercise as a measure of cardiac reserve. Subjects with elevated C-reactive protein (CRP) levels showed significantly worse impairments in cardiac systolic and diastolic function. Abbreviations: $L V E F=$ left-ventricular ejection fraction; $h s C R P=$ high-sensitivity $C$-reactive protein; $\mathrm{e}^{\prime}=$ early diastolic mitral annular velocities averaged between the lateral and septal annulus; $\triangle$ LVOT VTI CO = delta left-ventricular outflow tract velocity time integral cardiac output with exercise 

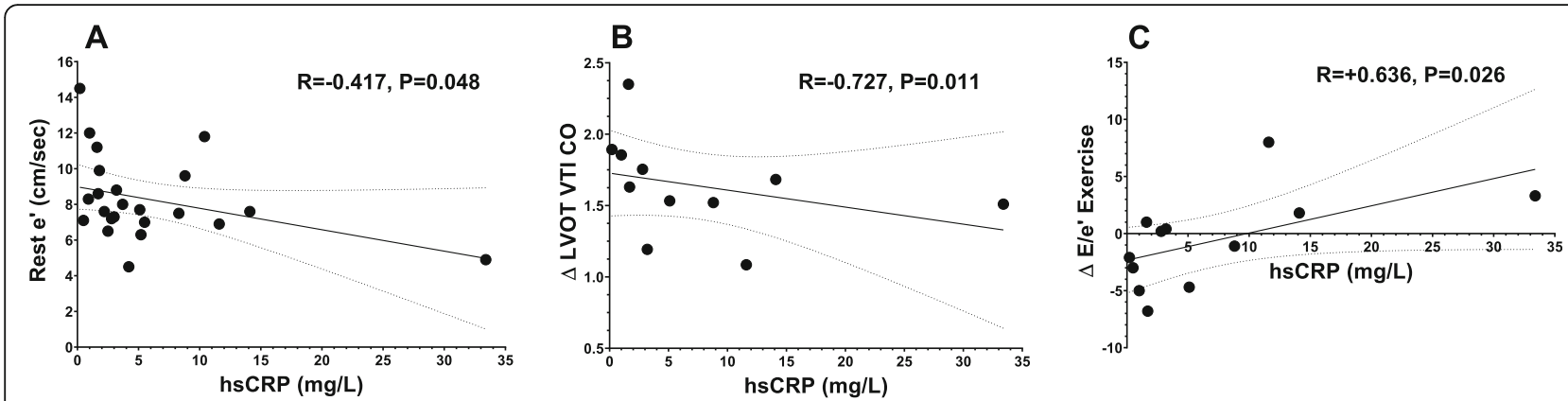

Fig. 2 Correlations of cardiac function with high-sensitivity C-reactive protein. High-sensitivity CRP levels as a continuous variable inversely correlated with the Doppler e' velocity (Panel a) and $\triangle$ LVOT VTI CO with exercise (Panel b), and directly with the $\Delta$ exercise E/e' ratio (Panel c). Abbreviations: $\mathrm{e}^{\prime}=$ early diastolic mitral annular velocities averaged between the lateral and septal annulus; hsCRP = high-sensitivity C-reactive protein; $\Delta$ LVOT VTI $\mathrm{CO}=$ delta left-ventricular outflow tract velocity time integral cardiac output with exercise; $\Delta \mathrm{E} / \mathrm{e}^{\prime}$ exercise = delta early transmitral flow to early diastolic mitral annular velocity ratio with exercise

(93 [81-101] \% vs. 95 [74-110] \%, $P=0.742$ ). Additionally, there were no significant differences between those with and without elevated hsCRP respective to presence of comorbid conditions, statin, or hormone therapy use (Table 2). Finally, none of the subjects had known active or progressive disease at the time of study participation.

Patients with elevated hsCRP had significantly lower LVEF (51 [44-59] \% vs. 61 [52-64] \%, $P=0.039$ ), e' velocity (7.4 [6.6-7.9] $\mathrm{cm} / \mathrm{sec}$ vs. $9.9[8.3-12.0] \mathrm{cm} / \mathrm{sec}, P=0.010)$, and $\Delta$ LVOT VTI CO with exercise $(+1.5[1.2-1.7] \mathrm{L} / \mathrm{min}$ vs +1.9 $[1.7-2.2] \mathrm{L} / \mathrm{min}, P=0.024)$, respectively compared to those with hsCRP $<2 \mathrm{mg} / \mathrm{L}$. Figure 1 illustrates the differences in LVEF (Panel A), impaired diastolic function as shown by lower e' values (Panel B), and reduced cardiac reserve (Panel C). In Fig. 2, hsCRP levels as a continuous variable inversely correlated with the Doppler e' velocity $(\mathrm{R}=-0.417, P=0.048$; Panel A) and $\Delta$ LVOT VTI CO with exercise $(\mathrm{R}=-0.727$, $P=0.011$; Panel B), and directly with the Doppler-derived estimated intra-cardiac pressures with exercise, $\Delta$ exercise $E /$ e' ratio $(\mathrm{R}=+0.636, P=0.026$; Panel $\mathrm{C})$.

\section{Discussion}

Radiotherapy is an integral treatment modality for many cancers. The relationship between ionizing radiation, inflammation and cardiotoxicity is complex and incompletely understood [27]. A number of acute effects including endothelial damage followed by inflammatory cell infiltration with subsequent fibrotic changes have been described. Systemic inflammation following radiotherapy has been associated with transient cardiac dysfunction including HF [17] and elevated pre-treatment serum CRP levels have been associated with poorer prognosis in esophageal cancer patients [28]. Moreover, cross-sectional studies in breast cancer survivors have shown a correlation between elevation in the proinflammatory markers CRP and IL-1 receptor antagonist and persistent post-treatment fatigue [29].
Here we show that elevated CRP levels are common and correlate with measures of impaired cardiac function in patients who have received thoracic radiotherapy for the treatment of cancer. These results suggest that changes in CRP and cardiac function can serve as early markers of cardiotoxicity following radiotherapy, and could potentially serve as useful biomarkers for outcome prediction. The limitations of this study are its small sample size and cross-sectional nature thus the observed associations do not prove causality.

In conclusion, further studies are needed to develop improved detection methods and ultimately treatments for subclinical cardiotoxicity in patients who have undergone radiation therapy to prevent long-term cardiac sequelae. Gaining a better understanding of the relationship between CRP and cardiac function in patients who have undergone radiation therapy could potentially help to optimize treatment, and ideally, serve as therapeutic targets to minimize long-term unwanted cardiac side-effects. IL-1 blockers are being studied for the prevention and treatment of heart failure, showing a promising safety and efficacy profile [30-35] thus introducing the possibility of future clinical trials investigating IL-1 blockade to treat patients at risk for radiation-induced heart failure.

\section{Abbreviations \\ $\triangle$ : Delta; E: Early transmitral velocity; e': Early diastolic mitral annular velocity; \\ Gy: Gray; HF: Heart failure; hsCRP: High-sensitivity C-reactive protein; IL- \\ 1: Interleukin-1; IQR: Interquartile range; LVEF: Left-ventricular ejection \\ fraction; LVOT VTI CO: Left-ventricular outflow tract velocity time integral \\ cardiac output; MCRD: Mean cardiac radiation dose}

\section{Acknowledgments}

The authors would like to thank all the patients and the families in the Virginia Commonwealth University Massey Cancer Center who participated in this study. The authors would also like to thank the staff of the Virginia Commonwealth University Clinical Research Unit and Massey Cancer for their support during the conduct of the study.

\section{Authors' contributions}

All authors have approved this manuscript for publication. GKT had a role in the analysis plan, interpretation of data, and manuscript writing; CRT, SC, HB 
had a role in acquisition of data, and manuscript writing; RKE, RG, BVT had a role in study conception, design, and analysis and interpretation of data, and manuscript writing; JMC, EW, AA had a role in study conception, design, acquisition of data, analysis and interpretation of data, and manuscript writing.

\section{Funding}

This research was supported through a Virginia Commonwealth University Massey Cancer Center Pilot Project grant \#P30CA016059K and Virginia Commonwealth University's grant \#1UL1TR002649 from the National Center for Advancing Translational Science. Dr. Carbone is supported by a Career Development Award 19CDA34660318 from the American Heart Association. Dr. Thomas is supported by the Virginia Commonwealth University Department of Internal Medicine Rising Scholar Program.

\section{Availability of data and materials}

The dataset analyzed during the current study are available from the corresponding author upon reasonable request.

\section{Ethics approval and consent to participate}

This research involved human subjects and was performed in accordance with the Declaration of Helsinki. All participants provided informed consent. This study was approved by the Institutional Review Board of Virginia Commonwealth University.

\section{Consent for publication}

Not applicable.

\section{Competing interests}

AA has served as a consultant for Astra Zeneca, Janssen, Merck, Novartis, Olatec, and Serpin pharma. BVT has served as a consultant for Novartis and Serpin Pharma.

The remaining authors have nothing to disclose in regards to this study and no conflicts of interest exist for all listed authors.

\section{Author details}

${ }^{1}$ VCU Pauley Heart Center, Virginia Commonwealth University, P.O. Box 980335, 1200 E. Broad Street, Richmond, Virginia 23298, USA. ²Department of Kinesiology \& Health Sciences, College of Humanities \& Sciences, Virginia Commonwealth University, Richmond, Virginia, USA. ${ }^{3}$ Department of Pharmacotherapy and Outcome Sciences, Virginia Commonwealth University, Richmond, Virginia, USA. ${ }^{4}$ Department of Radiation Oncology, Virginia Commonwealth University, Richmond, Virginia, USA. ${ }^{5} \mathrm{C}$. Kenneth and Dianne Wright Center for Clinical and Translational Research, Virginia Commonwealth University, Richmond, Virginia, USA.

Received: 2 January 2020 Accepted: 3 February 2020

Published online: 28 February 2020

\section{References}

1. Atkins KM, Rawal B, Chaunzwa TL, Lamba N, Bitterman DS, Williams CL, et al. Cardiac radiation dose, cardiac disease, and mortality in patients with lung Cancer. J Am Coll Cardiol. 2019;73(23):2976-87.

2. Xu C, Guo L, Liao Z, Wang Y, Liu X, Zhao S, et al. Heart and lung doses are independent predictors of overall survival in esophageal cancer after chemoradiotherapy. Clin Transl Radiat Oncol. 2019;17:17-23.

3. Drost L, Yee C, Lam H, Zhang L, Wronski M, McCann C, et al. A systematic review of heart dose in breast radiotherapy. Clin Breast Cancer. 2018;18(5): e819-24.

4. McCloskey SA, Yang GY. Benefits and challenges of radiation therapy in gastric cancer: techniques for improving outcomes. Gastrointest Cancer Res. 2009;3(1):15-9.

5. Wang K, Eblan MJ, Deal AM, Lipner M, Zagar TM, Wang Y, et al. Cardiac toxicity after radiotherapy for stage III non-small-cell lung cancer: pooled analysis of dose-escalation trials delivering 70 to 90 Gy. J Clin Oncol. 2017;35(13):1387-94.

6. Yeh ETH, Vejpongsa P. Subclinical Cardiotoxicity Associated With Cancer Therapy: Early Detection and Future Directions. J Am Coll Cardiol. 2015;65:2523-5.

7. Groarke JD, Nguyen PL, Nohria A, Ferrari R, Cheng S, Moslehi J. Cardiovascular complications of radiation therapy for thoracic malignancies: the role for non-invasive imaging for detection of cardiovascular disease. Eur Heart J. 2014; 35(10):612-23.
8. Bouillon K, Haddy N, Delaloge S, Garbay J-R, Garsi J-P, Brindel P, et al. Longterm cardiovascular mortality after radiotherapy for breast cancer. J Am Coll Cardiol. 2011;57(4):445-52.

9. Saiki H, Petersen IA, Scott CG, Bailey KR, Dunlay SM, Finley RR, et al. Risk of heart failure with preserved ejection fraction in older women after contemporary radiotherapy for breast Cancer. Circulation. 2017;135(15): 1388-96.

10. Kodama S, Saito K, Tanaka S, Maki M, Yachi Y, Asumi M, et al. Cardiorespiratory fitness as a quantitative predictor of all-cause mortality and cardiovascular events in healthy men and women: a meta-analysis. JAMA. 2009;301(19):2024-35.

11. Del Buono MG, Arena R, Borlaug BA, Carbone S, Canada JM, Kirkman DL, et al. Exercise intolerance in patients with heart failure. J Am Coll Cardiol. 2019;73(17):2209-25.

12. Jones LW, Courneya KS, Mackey JR, Muss HB, Pituskin EN, Scott JM, et al. Cardiopulmonary function and age-related decline across the breast cancer survivorship continuum. J Clin Oncol. 2012 Jul:30(20):2530-7.

13. Canada JM, Trankle CR, Carbone S, Buckley LF, Medina de Chazal H, Billingsley $\mathrm{HE}$, et al. Determinants of Cardiorespiratory Fitness Following Thoracic Radiotherapy in Lung or Breast Cancer Survivors. Am J Cardiol. 2019. https://doi.org/10.1016/j.amjcard.2019.12.019. [Epub ahead of print].

14. Samuel SR, Maiya AG, Fernandes DJ, Guddattu V, Saxena PUP, Kurian JR, et al. Effectiveness of exercise-based rehabilitation on functional capacity and quality of life in head and neck cancer patients receiving chemoradiotherapy. Support Care Cancer. 2019;27(10):3913-20.

15. Suesada MM, Carvalho H. de a, Albuquerque ALP de, Salge JM, Stuart SR, Takagaki TY. Impact of thoracic radiotherapy on respiratory function and exercise capacity in patients with breast cancer. J Bras Pneumol publicacao Of da Soc Bras Pneumol e Tisilogia. 2018;44(6):469-76.

16. Andersson C, Vasan RS. Epidemiology of heart failure with preserved ejection fraction. Heart Fail Clin. 2014;10(3):377-88.

17. Mezzaroma E, Mikkelsen RB, Toldo S, Mauro AG, Sharma K, Marchetti C, et al. Role of Interleukin-1 in radiation-induced cardiomyopathy. Mol Med. 2015;21:210-8.

18. Mezzaroma E, Weiss E, Mikkelsen R, Gewirtz DA, Canada J. Disentangling the Mechanisms of Radiation-Induced Heart Disease in the Treatment of Breast Cancer. Transl Med. 2015;5:152. https://doi.org/10.4172/2161-1025.1000152.

19. Szekely $Y$, Arbel $Y$. A review of Interleukin-1 in heart disease: where do we stand today? Cardiol Ther. 2018;7(1):25-44.

20. Han X, Zhou Y, Liu W. Precision cardio-oncology: understanding the cardiotoxicity of cancer therapy. NPJ Precis Oncol. 2017;1(1):31.

21. Toldo S, Mezzaroma E, Bressi E, Marchetti C, Carbone S, Sonnino C, et al. Interleukin-1beta blockade improves left ventricular systolic/diastolic function and restores contractility reserve in severe ischemic cardiomyopathy in the mouse. J Cardiovasc Pharmacol. 2014;64(1):1-6.

22. Van Tassell BW, Arena RA, Toldo S, Mezzaroma E, Azam T, Seropian IM, et al. Enhanced interleukin-1 activity contributes to exercise intolerance in patients with systolic heart failure. PLoS One. 2012;7:e33438-3.

23. Ridker PM, Danielson E, Fonseca FAH, Genest J, Gotto AMJ, Kastelein JJP, et al. Rosuvastatin to prevent vascular events in men and women with elevated C-reactive protein. N Engl J Med. 2008;359(21):2195-207.

24. Nagueh SF, Smiseth OA, Appleton CP, Byrd BF, Dokainish H, Edvardsen T, et al. Recommendations for the evaluation of left ventricular diastolic function by echocardiography: an update from the American Society of Echocardiography and the European Association of Cardiovascular Imaging. J Am Soc Echocardiogr. 2016;29(4):277-314.

25. Quinones MA, Otto CM, Stoddard M, Waggoner A, Zoghbi WA. Recommendations for quantification of Doppler echocardiography: a report from the Doppler quantification task force of the nomenclature and standards Committee of the American Society of echocardiography. J Am Soc Echocardiogr. 2002;15(2):167-84.

26. Haites NE, McLennan FM, Mowat DH, Rawles JM. Assessment of cardiac output by the Doppler ultrasound technique alone. Br Heart J. 1985;53(2):123-9.

27. Slezak J, Kura B, Babal P, Barancik M, Ferko M, Frimmel K, et al. Potential markers and metabolic processes involved in the mechanism of radiationinduced heart injury. Can J Physiol Pharmacol. 2017;95(10):1190-203.

28. Zheng T-L, Cao K, Liang C, Zhang K, Guo H-Z, Li D-P, et al. Prognostic value of $\mathrm{C}$-reactive protein in esophageal cancer: a meta-analysis. Asian Pac J Cancer Prev. 2014;15(19):8075-81.

29. Bower JE, Ganz PA, Tao ML, Hu W, Belin TR, Sepah S, et al. Inflammatory biomarkers and fatigue during radiation therapy for breast and prostate cancer. Clin Cancer Res. 2009;15(17):5534-40. 
30. Buckley LF, Abbate A. Interleukin-1 blockade in cardiovascular diseases: a clinical update. Eur Heart J. 2018;39(22):2063-9.

31. Abbate A, Kontos MC, Abouzaki NA, Melchior RD, Thomas C, Van Tassell BW, et al. Comparative safety of interleukin-1 blockade with anakinra in patients with ST-segment elevation acute myocardial infarction (from the VCU-ART and VCU-ART2 pilot studies). Am J Cardiol. 2015;115(3):288-92.

32. Abbate A, Van Tassell BW, Biondi-Zoccai G, Kontos MC, Grizzard JD, Spillman DW, et al. Effects of interleukin-1 blockade with anakinra on adverse cardiac remodeling and heart failure after acute myocardial infarction [from the Virginia Commonwealth University-Anakinra remodeling trial (2) (VCU-ART2) pilot study]. Am J Cardiol. 2013;111(10):1394-400.

33. Trankle CR, Canada JM, Cei L, Abouzaki N, Oddi-Erdle C, Kadariya D, et al. Usefulness of Canakinumab to improve exercise capacity in patients with long-term systolic heart failure and elevated C-reactive protein. Am J Cardiol. 2018:122(8):1366-70.

34. Everett BM, Cornel JH, Lainscak M, Anker SD, Abbate A, Thuren T, et al. Antiinflammatory therapy with Canakinumab for the prevention of hospitalization for heart failure. Circulation. 2019;139(10):1289-99.

35. Abbate A, Trankle C, Buckley L, Lipinski M, Appleton D, Kadariya D, et al. Interleukin-1 blockade Inhibits the Acute Inflammatory Response in Patients with ST-segment Elevation Myocardial Infarction. J Am Heart Assoc. 2020; In Press.

\section{Publisher's Note}

Springer Nature remains neutral with regard to jurisdictional claims in published maps and institutional affiliations.

Ready to submit your research? Choose BMC and benefit from:

- fast, convenient online submission

- thorough peer review by experienced researchers in your field

- rapid publication on acceptance

- support for research data, including large and complex data types

- gold Open Access which fosters wider collaboration and increased citations

- maximum visibility for your research: over $100 \mathrm{M}$ website views per year

At $\mathrm{BMC}$, research is always in progress.

Learn more biomedcentral.com/submissions 